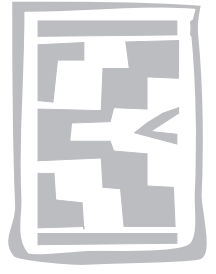

\title{
Identification and partial sequencing of a crocodile poxvirus associated with deeply penetrating skin lesions in farmed Nile crocodiles, Crocodylus niloticus
}

\author{
F.W. HUCHZERMEYER ${ }^{1 *}$, D.B. WALLACE ${ }^{2,3}$, J.F. PUTTERILL ${ }^{2}$ and G.H. GERDES ${ }^{2}$
}

\begin{abstract}
HUCHZERMEYER, F.W., WALLACE, D.B., PUTTERILL, J.F. \& GERDES, G.H. 2009. Identification and partial sequencing of a crocodile poxvirus associated with deeply penetrating skin lesions in farmed Nile crocodiles, Crocodylus niloticus. Onderstepoort Journal of Veterinary Research, 76:311316

When large numbers of crocodile skins were downgraded because of the presence of small pin pricklike holes, collapsed epidermal cysts were found deep in the dermis of juvenile crocodiles while forming cysts were observed in hatchlings. Histopathology of these forming cysts showed the presence of intracytoplasmic inclusions in proliferating and ballooning epidermal cells. Pox virions were seen in electron microscope preparations made from the scabs of such early lesions. The partial sequencing of virus material from scrapings of these lesions and comparison of it with the published sequence of crocodile poxvirus showed the virus associated with the deep lesions to be closely related, but different. To differentiate between the two forms of crocodile pox infection it is suggested that the previously known form should be called "classical crocodile pox" and the newly discovered form "atypical crocodile pox". The application of strict hygiene measures brought about a decline in the percentage of downgraded skins.
\end{abstract}

Keywords: Crocodylus niloticus, dermatitis, electron microscopy, genome sequencing, poxvirus

\section{INTRODUCTION}

In Nile crocodiles (Crocodylus niloticus), crocodile poxvirus (CRV) infection causes small, superficial skin lesions covered by dark brownish crusts or scabs. Microscopically the lesions are characterised by the presence of masses of intracytoplasmic inclusions in proliferating epidermis cells (Horner 1988; Huchzermeyer, Huchzermeyer \& Putterill

* Author to whom correspondence is to be directed. E-mail: crocvet@mweb.co.za

1 P.O. Box 12499, Onderstepoort, 0110 South Africa

2 Onderstepoort Veterinary Institute, Private Bag X05, Onderstepoort, 0110 South Africa

3 Department of Veterinary Tropical Diseases, Faculty of Veterinary Science, University of Pretoria, Private Bag X04, Onderstepoort, 0110 South Africa

Accepted for publication 19 February 2009-Editor
1991). The morphology of CRV particles in negatively stained preparations was described by Gerdes (1991) and in 2006, Afonso, Tulman, Delhon, Lu, Viljoen, Wallace, Kutish \& Rock published the genomic sequence of $\mathrm{CRV}$ from $C$. niloticus.

Minute superficial lesions, below which were deeply penetrating holes found in skins of American alligators (Alligator mississippiensis) were dubbed "pix" (Dickson, Cardeilhac \& Ashley 2002). They were believed to be a manifestation of a lymphohistiocytic proliferative syndrome associated with West Nile virus infection (Nevarez, Mitchell, Johnson \& Kinler 2007). Similar pin prick-like lesions were found in Nile crocodile skins and dubbed "pit holes" (Huchzermeyer \& Putterill 2004). Affected skins are downgraded which has severe financial implications for the farmer. This paper describes the histopathology of these lesions, the morphological 
identification of a poxvirus from these lesions and its comparison with CRV using partial sequence analysis.

\section{MATERIALS AND METHODS}

Three tanned crocodile skins were made available for gross examination of the skin lesions ("pit holes") and photography.

One affected crocodile from each of four age groups, three-, two-, one-year and hatchlings were selected by examination of their ventral skin. These animals were killed by an approved slaughter technique. They were skinned and samples of skin with visible lesions were fixed in $10 \%$ phosphate buffered formalin. An additional affected hatchling was selected in a similar manner to that mentioned above and scrapings were taken from some of the visible skin lesions. In order to obtain additional material for study purposes, skin samples were excised from affected crocodiles during subsequent routine post mortem examinations.

\section{Light microscopy}

The formalin-fixed skin samples were routinely processed for light microscopy. Sections were cut at ca $6 \mu \mathrm{m}$ thickness, stained with haematoxylin and eosin, and examined using a Leica DM-6000B compound light microscope (Leica Microsystems, IR, GmbH).

\section{Electron microscopy}

Unfixed scrapings from the crust of a recently formed lesion in the skin of a hatchling crocodile were homogenised using an Ultra-Turrax homogeniser (Janke \& Kunkel, Ika-Werk, GmbH \& Co KG, Staufen) in double distilled water and routinely prepared for negative staining. Low speed centrifugation was used to remove coarse detritus. After ultra-centrifugation of the supernatant, the resultant pellet was resuspended in $3 \%$ phospho-tungstic acid (PTA) at $\mathrm{pH}$ 6.4, applied to Formvar coated copper grids and examined using a Jeol JEM-1200EX Mk-I transmission electron microscope (Jeol, Tokyo, Japan) at $80 \mathrm{kV}$.

\section{Partial sequencing of the virion gene}

DNA was extracted from virions in the scrapings according to an adapted method of Esposito, Condit \& Obijeski (1981). Lesion scrapings were added to phosphate-buffered saline (PBS) and ground with diatomaceous earth using a mortar and pestle. The emulsified solution was cleared by low speed centrifugation in a Beckman Avanti (Beckman, USA) bench-top centrifuge (2 $000 \mathrm{rpm}$ [450 g] for $2 \mathrm{~min}$ ). The supernatant fraction was diluted 1:1 in viral-lysis buffer consisting of $1 \%$ SDS (Sigma, USA), $20 \mathrm{mM}$ $\beta$-mercaptoethanol (Merck, Germany), and $20 \mathrm{mM}$ EDTA. Proteinase-K (Roche, Germany) (at a final concentration of $100 \mu \mathrm{g} / \mathrm{ml}$ ) was added and the mixture was incubated at $56^{\circ} \mathrm{C}$ for $2 \mathrm{~h}$ in order to release viral DNA. Calf liver tRNA $(0.5 \mu l$ of a $10 \mathrm{mg} /$ $\mathrm{m} \ell$ stock) (Roche, Germany) and $1 / 10^{\text {th }}$ volume $3 \mathrm{M}$ sodium acetate ( $\mathrm{pH}$ 5.3) was added and the DNA extracted with phenol/chloroform (Sigma, USA), and precipitated with 2.5 volumes $96 \%$ ethanol. After air-drying, the DNA was resuspended in $50 \mu \ell$ sterile, ultra-pure HPLC-quality water (Sigma, USA) and stored at $-20^{\circ} \mathrm{C}$ for PCR analysis.

\section{PCR analysis of viral DNA}

For the design of primers, a unique region of crocodile poxvirus (CRV) open reading frame (ORF) 019 sequence was chosen (Afonso et al. 2006). Two oligonucleotide primers were designed (Zcp1F CTA GAC GAA GAA CTG GTA C, Zcp1R - GGA GAT CTT GGT GCG GTA) covering a 577 base pair (bp) region of ORF019. PCR amplification was carried out using these primers and a GeneAmp 2400 thermal cycler (Perkin-Elmer, USA). A $50 \mu$ l reaction volume was prepared consisting of $5 \mu \ell 10 X$ PCR buffer (containing $20 \mathrm{mM} \mathrm{MgCl}$ ) (Takara Biomed-

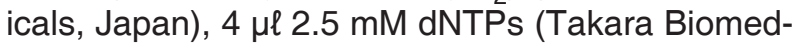
icals, Japan), $0.5 \mathrm{U}$ Taq DNA polymerase (TaKaRa Ex Taq $^{\mathrm{TM}}$, Takara Biomedicals, Japan), $1 \mu \ell$ of each primer (20 pmoles of each), $1 \mu \ell$ of template DNA $(\sim 0.1 \mathrm{ng})$ and $38 \mu \ell$ sterile ultra-pure HPLC-quality water (Sigma, USA). Template DNA was denatured for $60 \mathrm{~s}$ at $95^{\circ} \mathrm{C}$, followed by 35 cycles of denaturation at $95^{\circ} \mathrm{C}$ for $15 \mathrm{~s}$, primer annealing at $56^{\circ} \mathrm{C}$ for $45 \mathrm{~s}$, and strand extension at $72^{\circ} \mathrm{C}$ for $60 \mathrm{~s}$.

\section{Sequencing and analysis of PCR-amplified viral DNA}

For sequence analysis, primer Zcp1F was chosen as sequencing primer. PCR-amplified DNA was purified using a QIAquick spin column (Qiagen, Germany) and $10 \mathrm{ng}$ was added to 3.2 pmoles primer in a $12 \mu$ l reaction volume. Sequencing was performed using an ABI Prism 3100 Genetic Analyser (Hitachi, Japan) and BigDye ${ }^{T M}$ chemistry from a BigDye ${ }^{T M}$ Terminator cycle sequencing kit (Applied Biosystems, USA). Sequence data was then aligned and compared with the published CRV sequence (Afonso et al. 2006). 


\section{RESULTS}

\section{Macroscopic}

In tanned crocodile skins, small deep pin prick-like holes were found randomly distributed in some of the smooth scales of the ventral skin (Fig. 1). The pit holes were distinct from the sensory pores which are found usually one to each ventral scale situated close to its caudal edge (Fig. 1) and which are not deep holes.

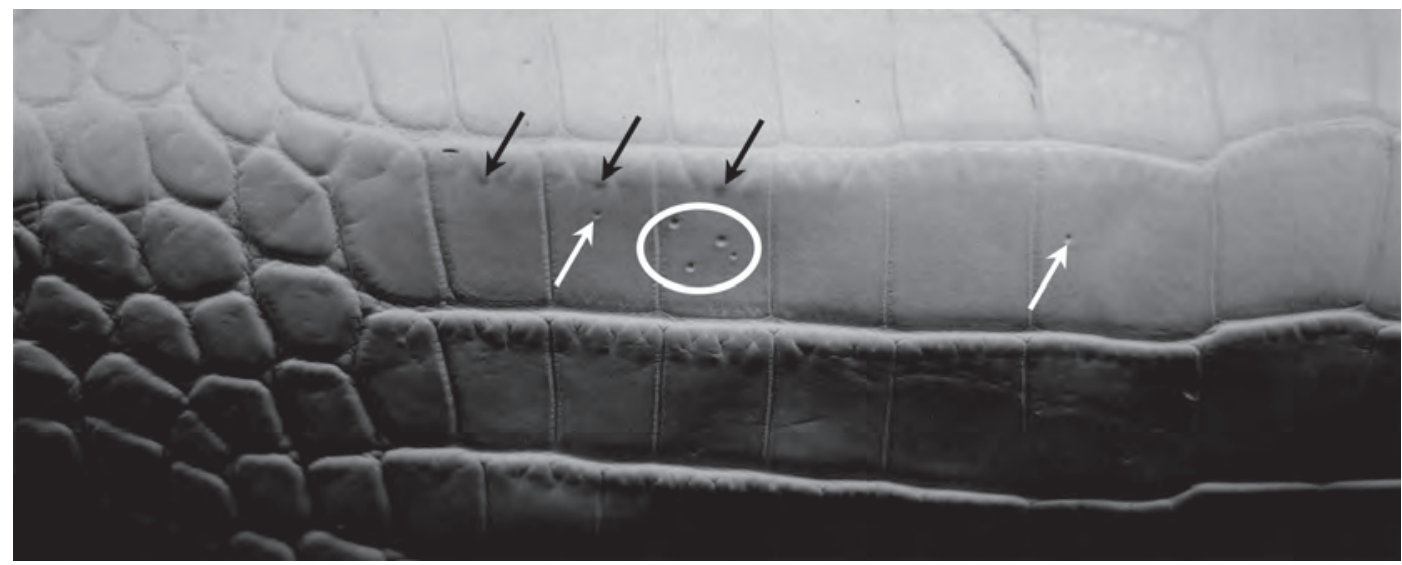

FIG. 1 Pit holes (encircled area and white arrows) in ventral scales of tanned Nile crocodile skin and showing sensory pores close to the caudal margin of the scales (black arrows), $0.75 \mathrm{X}$
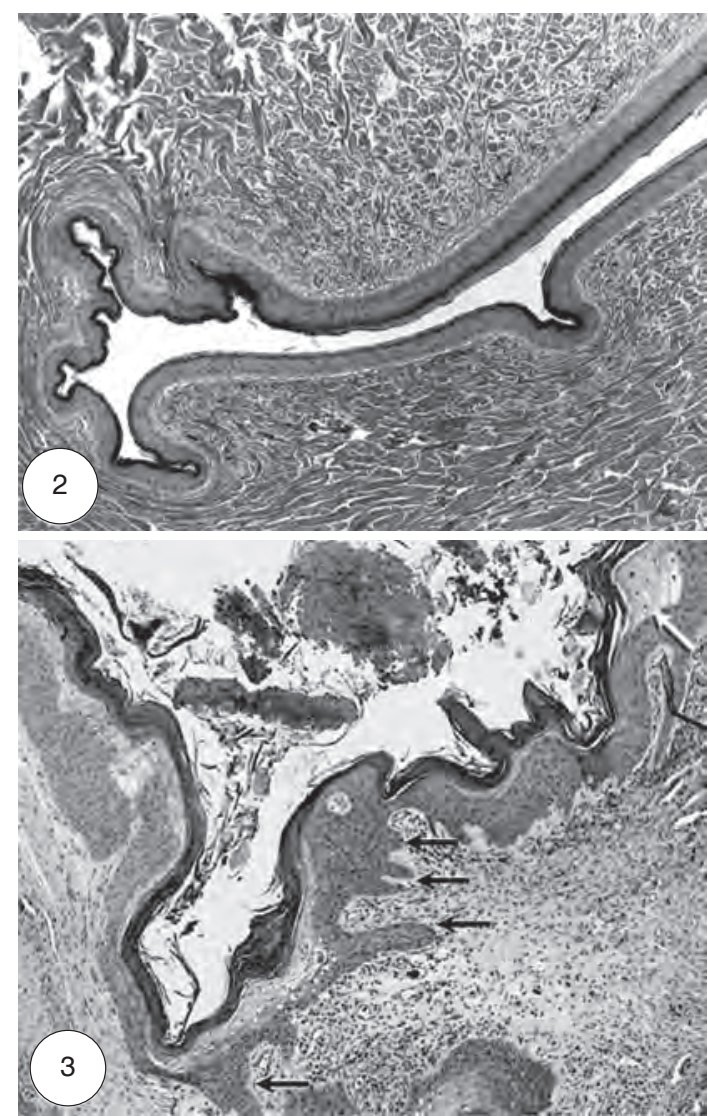

FIG. 2 Collapsed and healed cyst in the dense dermis. Its epidermal lining signifies healing, 10X

FIG. 3 Part of a newly forming cyst in hatchling skin. Note the finger-like epidermal projections (columns) penetrating further into the dermis (black arrows). Several inclusion bodies are indicated by the white arrows, $5 \mathrm{X}$



FIG. 4 Intracytoplasmic inclusions in the proliferating epidermal cells in a newly formed cyst, indicated by the arrows, $10 \mathrm{X}$

FIG. 5 An early stage of a newly forming cyst with intracytoplasmic inclusion bodies. $\mathrm{F}$ is a fold artefact induced by sectioning, 10X 


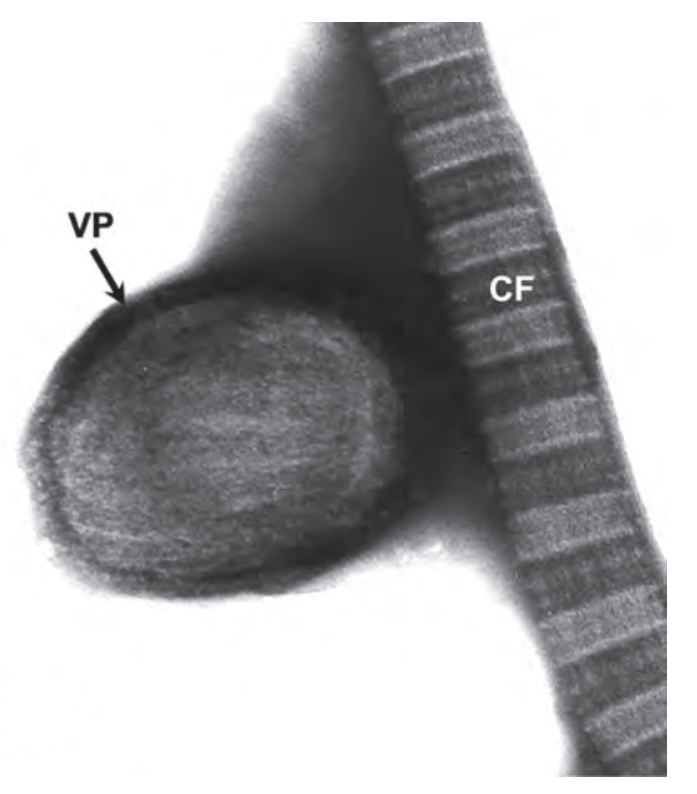

FIG. 6 Crocodile poxvirus particle attached to a collagen fibre from the crust covering a newly formed cyst. CF - collagen fibre; VP - virus particle, 40 000X

\section{Histopathology}

The histopathology of the skin lesions of the threeyear-old and two-year-old crocodiles consisted of collapsed cysts with a folded surface that was lined entirely by a complete epidermis without any trace of an inflammatory reaction (Fig. 2). The skin of the one-year-old crocodile showed similar collapsed cysts, each with a healed surface. However, under the epidermis there were small perivascular infiltrations of lymphocytes. In the skin of the hatchling crocodiles there were debris-filled cysts, partially lined by an apparently proliferating epidermis. This epidermis appeared to form extending columns of cells deep into the dermis (Fig. 3) and, in one region, the proliferating epidermal cells were ballooned and contained intracytoplasmic inclusion bodies (Fig. 4). In a subsequent routine post mortem case, newly formed cysts were found to be packed entirely with ballooning cells containing intracytoplasmic inclusions (Fig. 5).

\section{Electron microscopy}

Electron microscopic examination of the scrapings from the edge of these lesions revealed the presence of pox virions with cross striations, typical of those found with CRV. The accompanying micrograph (Fig. 6) is of the slightly larger C-form where stain has partially penetrated the particle obscuring detail of the surface thread. The double membrane or outer coat of the particle is, however, visible.

\section{Viral DNA}

DNA isolated from the scrapings was PCR-amplified and analysed using agarose gel electrophoresis. Only the predicted amplification product of $577 \mathrm{bp}$ was obtained (data not shown). The amplified DNA was purified, sequenced and the resulting sequence (533 bp) aligned with CRV (Fig. 7). As expected, the sequence aligned within ORF019 of CRV (Afonso et al. 2006). At the nucleotide level (Fig. 7A) there are seven differences, relating to five at the amino acid level (Fig. 7B).

\section{DISCUSSION}

The epidermis of the crocodilian skin consists of straight layers of squamous cells without epidermal ridges embracing dermal papillae. The epidermis is covered by tough rigid scale-keratin over the scales and by a more flexible interscale keratin in the folds between the scales (Richardson, Webb \& Manolis 2002). In previously described cases of crocodile poxvirus infections in Nile crocodiles, there were circumscribed lesions with severe proliferation of the epidermis, causing a depression into the underlying loose dermis with occasional ulceration. In the proliferating and ballooning epidermal cells, large numbers of intracytoplasmic inclusions, comprising greater numbers of Bollinger bodies and fewer Borrel bodies were found (Horner 1988; Huchzermeyer et al. 1991; Buoro 1992; Pandey, Inoue, Ohshima, Okada, Chihaya \& Fujimoto 1990). These lesions do not cause permanent scars in the tanned skin. In contrast, the lesions found in the present investigation penetrated deeply through the loose dermis and into the dense dermis causing cysts to develop that collapsed at a later stage but did not close or heal completely. This penetration was accompanied by extended columns of epidermal cells. Even after the healing of the ulcers, the deeply sited cysts collapsed, but remained as permanent lesions comprising the "holes" seen macroscopically in the tanned skins. In the first cases examined, only a few ballooning epidermal cells at the entrance of the cysts appeared to contain Bollinger and Borrel bodies. For this reason it was deemed necessary to examine crust-scrapings utilising electron microscopy. However, in a subsequent case that was examined, cysts completely filled with ballooning epidermis cells containing intracytoplasmic inclusions were encountered. The intimate association between the manifestations of crocodile poxvirus infection and the deep cysts leaves little doubt regarding the causative role of the poxvirus, particularly in the absence of the pathogenic West Nile virus in southern Africa. 


\begin{abstract}
A
CRV CTGGTACGTCGCGGTCGGCTCCTCTTCCGGGTCGCGCGCGGAGGCGGTGAAGGCGTTGAT 60 Pit CTGGTACGTCGCGGTCGGCTCCTCTTCCGGGTCGCGCGCGGAGGCGGTGAAGGCGTTGAT 60

CRV CGCGTCGATGCCGGCGGCCGAAAAAATGTACGCGCAGGGATCTGGCGCGTCGGGGCTCGA 120 Pit CGCGTCGATGCCGGCGGCCGAAAAAATGTACGCGCAGGGATCGGGCGCGTCGGGGCTCGA 120 CRV GCACGCCATCATATCCATGGCGGCGTAGCGCGAGAAGTACTCCCGGGACAGCACGATTTG 180 Pit GCACGCCATCATGTCCATGGCGGCGTAGCGCGAGAAGTACTCCCGGGACAGCACGATTTG 180 *

CRV GTGCTCGTACGCGAAGGGCTCCTCCAGCGCCGAGACGGGGATCACGCGCATGATGGTCTC 240 Pit GTGCTCGTACGCGAAGGGCTCCTCCAGCGCCGAGACGGGGATCACGCGCATGATGGTCTC 240

CRV GACCGCGCCGAGCGCGTTCAGGAAGCGAAGGTACAGCGTCTCGCGCGTCTCGGGGCCCAG 300 Pit GACCGCGCCGAGCGCGTTCAGAAAGCGGAGGTACAGCGTTTCGCGCGTCTCGGGGCTCAG 300 CRV CGTGATGGAGACGCACAGCAAGTCGTGCCGGATCCCGCTCAGCGGCGGAAACCGGTCGTA 360 Pit CGTGATGGAGACGCACAGCAGGTCGTGCCGGATCCCGCTCAGCGGCGGAAACCGGTCGTA 360 $\star$

CRV CTCGACGATGGAGTGCTCGAACGGGTCGGCCGCGCCGTCCTCGTCCGGGTCGCTGCCGTC 420 Pit CTCGACGATGGAGTGCTCGAACGGGTCGGCCGCGCCGTCCTCGTCCGGGTCGCTGCCGTC 420 CRV GTCCACGTCGTCGCCGTCGGTGAAGTACCCGGCGTCGCCGCGCTCGGCCTCCAGCATCCC 480 Pit GTCCACGTCGTCGCCGTCGGTGAAGTACCCGGCGTCGCCGCGCTCGGCCTCCAGCATCCC 480

CRV GTCGCGCACGCCCGCGCGTCGATAGGCAGGGCGTCGTTTTTGATCGAGAACGT 533

Pit GTCGCGCACGCCCGCGCGTCGATAGGCAGGGCGTCGTTTTTGATCGAGAACGT 533

B

CRV LVRRGRLLFRVARGGGEGVDRVDAGGRKNVRAGIWRVGARARHHIHGGVAREVLPGQHDL 60 Pit LVRRGRLLFRVARGGGEGVDRVDAGGRKNVRAGIGRVGARARHHVHGGVAREVLPGQHDL 60

CRV VLVREGLLQRRDGDHAHDGLDRAERVQEAKVQRLARLGAQRDGDAQQVVPDPAQRRKPVV 120 Pit VLVREGLLQRRDGDHAHDGLDRAERVQKAEVQRFARLGAQRDGDAQQVVPDPAQRRKPVV 120

CRV LDDGVLERVGRAVLVRVAAVVHVVAVGEVPGVAALGLQHPVAHARASIGRASFLIEN 177 Pit LDDGVLERVGRAVLVRVAAVVHVVAVGEVPGVAALGLQHPVAHARASIGRASFLIEN 177
\end{abstract}

FIG. 7 Sequence alignment of a region of ORF 019 of CRV with the "pit" poxvirus (amplified using PCR) at the nucleotide level (A) and amino acid level (B). Differences in nucleotides $\left(^{*}\right)$ and amino acids (grey shading) are shown

In the United States of America, pitting of alligator skins was a cause of concern (Haire 1997). This was before the first outbreak of West Nile virus infection in alligators was reported in that country (Miller, Mauel, Baldwin, Burtle, Ingram, Hines \& Frazier 2003). This indicates the possibility that two different agents may cause similar permanent lesions.

Members of the poxvirus family cannot be assigned to different genera using electron microscopy and viral particles are generally compared morphologically to those of the well-described vaccinia virus which is the type species of the orthopox genus (Medzon \& Bauer 1970). The mature virion is brick to ovoid-shaped and measures 235-330 nm x 170$285 \mathrm{~nm}$. Two forms are recognized, the $\mathrm{M}$ or mulberry form and the $\mathrm{C}$ or capsule form (Doane \& Anderson 1987). Commonly, the outer envelope is absent, revealing the complex structure of the particle coat or membrane with irregularly arranged surface threads or double ridges outlined by the PTA stain (Gerdes 1991). The new virus seen in this investigation in its $\mathrm{C}$-form did not differ morphologically from the known crocodile poxvirus. 
The limited sequence data generated for this virus indicates that it is closely related to, but distinct from, the crocodile poxvirus, CRV. In view of the fact that there are two closely related crocodile poxviruses causing entirely different lesion morphologies, we propose the disease described in this paper to be called "atypical" crocodile pox and the previously described disease to be called "classical" crocodile pox. Whereas the "classical" crocodile pox infection is characterised by superficial lesions without permanent scars, the "atypical" crocodile pox infection causes deeply penetrating lesions and permanent scars or "pit holes".

The introduction of strict hygiene measures in the rearing houses on the affected farm, particularly thorough cleaning and disinfection of the pens resulted in a reduction in the percentage of downgraded skins. This has however, not resulted in the elimination of the infection from the farm.

\section{ACKNOWLEDGEMENTS}

Staff of the Pathology Section, Department of Paraclinical Sciences, Faculty of Veterinary Science, University of Pretoria are thanked for preparing and staining the skin sections.

\section{REFERENCES}

AFONSO, C.L., TULMAN, E.R., DELHON, G., LU, Z., VILJOEN, G.J., WALLACE, D.B., KUTISH, G.F. \& ROCK, D.L. 2006. Genome of crocodile pox virus. Journal of Virology, 80:49784991.

BUORO, I.B.J. 1992. Pox-like virus particles in skin lesions of five Nile crocodiles in Kenya. Discovery and Innovation, 4: 117-118.

DICKSON, H., CARDEILHAC, P. \& ASHLEY, J.D. 2002. Pix skin disease in the American alligator (Alligator mississippiensis), in Crocodiles. Proceedings of the $16^{\text {th }}$ Working Meeting of the Crocodile Specialist Group, IUCN - The World Conservation Union, Gland, Switzerland and Cambridge, UK: 187.

DOANE, F.W. \& ANDERSON, N. 1987. Poxviridae, in Electron microscopy in diagnostic virology. A practical guide and atlas. Cambridge: Cambridge University Press.

ESPOSITO, J., CONDIT, R. \& OBIJESKI, J. 1981. The preparation of Orthopoxvirus DNA. Journal of Virological Methods, 2:175-179.

GERDES, G.H. 1991. Morphology of poxviruses from reptiles. Veterinary Record, 128:452.

HAIRE, D. 1997. Concern over American alligator skin pitting. Crocodile Specialist Group Newsletter, 16:22-23.

HORNER, R.F. 1988. Poxvirus in farmed Nile crocodiles. Veterinary Record, 122:459-462.

HUCHZERMEYER, F.W., HUCHZERMEYER, K.D.A. \& PUTTERILL, J.F. 1991. Observations on a field outbreak of pox virus infection in young Nile crocodiles (Crocodylus niloticus). Journal of the South African Veterinary Association, 62: 27-29.

HUCHZERMEYER, F.W. \& PUTTERILL, J.F. 2004. Pitholes in Nile crocodile skins, in Crocodiles. Proceedings of the $17^{\text {th }}$ Working Meeting of the Crocodile Specialist Group, IUCN The World Conservation Union, Gland, Switzerland and Cambridge, UK: 492-493.

MEDZON, E.L. \& BAUER, H. 1970. Structural features of vaccinia virus revealed by negative staining, sectioning and freeze-etching. Virology, 40:860-867.

MILLER, D.L., MAUEL, M.J., BALDWIN, C., BURTLE, G., INGRAM, D., HINES, M.E. \& FRAZIER, K.S. 2003. West Nile virus in farmed alligators. Emerging Infectious Diseases, 9: 794-799.

NEVAREZ, J.G., MITCHELL, M.A., JOHNSON, A.J. \& KINLER, N. 2007. Establishing an association between West Nile virus exposure and the development of lymphohistiocytic proliferative syndrome in American alligators, Alligator mississippiensis. Journal of Herpetological Medicine and Surgery, 17:4-7.

PANDEY, G.S., INOUE, N., OSHIMA, K., OKADA, K., CHIHAYA, Y. \& FUJIMOTO, Y. 1990. Poxvirus infection in Nile crocodiles (Crocodylus niloticus). Research in Veterinary Science, 49:171-176.

RICHARDSON, K.C., WEBB, G.J.W. \& MANOLIS, S.C. 2002. Crocodiles: Inside out. Chipping Norton: Surrey Beatty and Sons. 